\section{Commentary: Is the glass half full or half empty?}

\author{
Monika Halas, MD, ${ }^{a}$ and Joseph S. Coselli, MD ${ }^{a, b, c}$
}

Spinal cord deficit (SCD), namely, paraplegia and paraparesis, remains one of the most debilitating complications in open distal aortic surgery. In 2016, Coselli and colleagues ${ }^{1}$ reported the risk of SCD after open thoracoabdominal aortic surgery, starting from $2.4 \%$ in extent IV to $8 \%$ in extent II in accordance with the Crawford classification. Despite the advances in technology, improved operative technique, and numerous prevention strategies, the prevalence of SCD remains a concern. Since the use of somatosensory evoked potentials (SSEPs) and motor evoked potentials (MEPs) to detect SCD during aortic surgery were first described, ${ }^{2,3}$ they have become established methods of protection and well studied ${ }^{4-6}$; however, their clinical utility remains debatable. The premise of SSEP and MEP involves neurophysiologically monitoring patients during aortic repair to detect a potential loss of signal, which portends an enhanced risk of SCD. When a loss of signal is detected during the procedure, hemodynamic and other adjustments are made to restore function to the spinal cord.

In this issue of the Journal, Tanaka and colleagues ${ }^{7}$ investigated the role of using motor and SSEPs in open distal aortic repairs. In this study of 822 patients undergoing open descending thoracic and thoracoabdominal aortic surgeries, the authors analyzed both SSEP and MEP signal

From the ${ }^{a}$ Cardiothoracic Surgery, Michael E. DeBakey Department of Surgery, Baylor College of Medicine, Houston, Tex; ${ }^{b}$ Department of Cardiovascular Surgery, Texas Heart Institute, Houston, Tex; and ${ }^{\mathrm{c}} \mathrm{CHI}$ St Luke's-Baylor St Luke's Medical Center, Houston, Tex.

Disclosures: J.S.C.'s work is partly supported by an endowment by the Cullen Foundation. J.S.C. consults for, receives royalties and a departmental educational grant from, and participates in clinical trials for Terumo Aortic; consults and participates in clinical trials for Medtronic, Inc, and WL Gore \& Associates; and serves as a coinvestigator for CytoSorbents. M.H. reported no conflicts of interest.

The Journal policy requires editors and reviewers to disclose conflicts of interest and to decline handling or reviewing manuscripts for which they may have a conflict of interest. The editors and reviewers of this article have no conflicts of interest.

Received for publication Aug 20, 2021; revisions received Aug 20, 2021; accepted for publication Aug 23, 2021; available ahead of print Aug 28, 2021.

Address for reprints: Joseph S. Coselli, MD, Cardiothoracic Surgery, Michael E. DeBakey Department of Surgery, Baylor College of Medicine, One Baylor Plaza, BCM 390, Houston, TX 77030 (E-mail: jcoselli@bcm.edu).

J Thorac Cardiovasc Surg 2023;165:954-5

$0022-5223 / \$ 36.00$

Copyright (c) 2021 by The American Association for Thoracic Surgery

https://doi.org/10.1016/j.jtcvs.2021.08.051

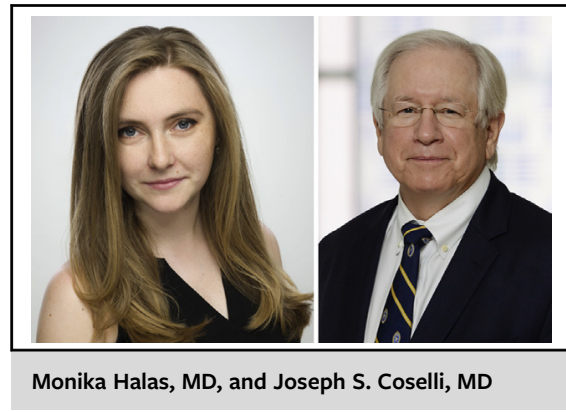

CENTRAL MESSAGE

SSEPs and MEPs are important tools in the detection of SCD.

measurements that were collected for more than 15 years and assessed their clinical relevance. The results were divided into immediate SCD and delayed SCD. Regarding immediate SCD, the loss of isolated MEP signals was observed in $1 \%(n=4 / 283)$ of the patients, and the loss of both MEPs and SSEPs was observed in 9\% $(n=15 /$ 173). Notably, none of the patients without a signal loss developed immediate SCD. For patients with delayed SCD, the isolated loss of MEP signals occurred in $19 \%$ $(\mathrm{n}=12 / 63)$ and the combined signal loss (MEP and SSEP $)$ in $81 \%(n=51 / 63)$ of the patients. However, 12 patients $(3 \%)(n=12 / 348)$ did not have any form of signal loss yet developed delayed SCD. The authors note that the loss of MEP was the most predictive of both types of SCD (with an odds ratio of 15.87). Interestingly, and importantly, this study shows a positive predictive value when MEPs are combined with SSEPs, in contrast to previous studies that showed no benefit with the addition of SSEP testing. ${ }^{4,8,9}$

Tanaka and coauthors ${ }^{7}$ give an insight to combined use of these monitoring techniques and provide an important contribution to the problem of SCD after open distal aortic repair. The use of neuromonitoring techniques has increased over time but is not routinely used during distal aortic procedures. ${ }^{10}$

So, is the glass half full or half empty? MEPs and SSEPs may indicate the need to perform additional procedures during the surgery to mitigate risk of SCD, but they are timeconsuming to use, are not perfectly precise, may result in false-positives (ie, leading the surgeon to pass up on the opportunity to reattach the internal carotid artery), and poorly 
suited for use in some clinical settings, such as in use during deep hypothermic conditions or with certain confounding anesthetic agents. Moreover, they require a highly experienced neurophysiologist in the operating room, and not all the institutions are able to successfully implement this technology, especially in the setting of emergency surgery. On the one hand, MEP and SSEP monitoring may sound an alarm that additional attention and action are rapidly needed, and their widespread implementation may lead to some decrease in this devastating complication. On the other hand, they may be of little use if strategies to maximize spinal cord function, such as the use of cerebrospinal fluid drainage, distal perfusion techniques, and reattachment of crucial arteries feeding the spinal cord, are universally used. ${ }^{1}$ The important question remains: Can we do better? With continued advances in medical technology, the use of more accurate and efficient methods to monitor perfusion of the spinal cord in real-time should become accessible for patients undergoing complex open distal aortic repairs. The potential to further reduce the risk of SCD remains. Assessing clinical settings using current technology and available resources to mitigate against the tragic complications of SCD is a mandate we cannot ignore.

\section{References}

1. Coselli JS, LeMaire SA, Preventza O, de la Cruz KI, Cooley DA, Price MD, et al. Outcomes of 3309 thoracoabdominal aortic aneurysm repairs. J Thorac Cardiovasc Surg. 2016;151:1323-37.
2. Cunningham JN Jr, Laschinger JC, Merkin HA, Nathan IM, Colvin S, Ransohoff J, et al. Measurement of spinal cord ischemia during operations upon the thoracic aorta: initial clinical experience. Ann Surg. 1982;196: 285-96.

3. de Haan P, Kalkman CJ, de Mol BA, Ubags LH, Veldman DJ, Jacobs MJ. Efficacy of transcranial motor-evoked myogenic potentials to detect spinal cord ischemia during operations for thoracoabdominal aneurysms. J Thorac Cardiovasc Surg. 1997;113:87-101.

4. Kawanishi Y, Munakata H, Matsumori M, Tanaka H, Yamashita T, Nakagiri K, et al. Usefulness of transcranial motor evoked potentials during thoracoabdominal aortic surgery. Ann Thorac Surg. 2007;83: 456-61.

5. Keyhani K, Miller CC III, Estrera AL, Wegryn T, Sheinbaum R, Safi HJ. Analysis of motor and somatosensory evoked potentials during thoracic and thoracoabdominal aortic aneurysm repair. J Vasc Surg. 2009;49:36-41.

6. Liu LY, Callahan B, Peterss S, Dumfarth J, Tranquilli M, Ziganshin BA, et al. Neuromonitoring using motor and somatosensory evoked potentials in aortic surgery. J Card Surg. 2016;31:383-9.

7. Tanaka A, Nguyen H, Dhillon JS, Nakamura M, Zhou S-F, Sanhu HK. AATS 2020: reappraisal of the role of motor and somatosensory evoked potentials during open distal aortic repair. J Thorac Cardiovasc Surg. 2023; 165:944-53.

8. Galla JD, Ergin MA, Lansman SL, McCullough JN, Nguyen KH, Spielvogel D, et al. Use of somatosensory evoked potentials for thoracic and thoracoabdominal aortic resections. Ann Thorac Surg. 1999;67: 1947-58.

9. Jacobs MJ, Mess W, Mochtar B, Nijenhuis RJ, Statius van Eps RG, Schurink GW. The value of motor evoked potentials in reducing paraplegia during thoracoabdominal aneurysm repair. J Vasc Surg. 2006; 43:239-46.

10. Etz CD, Weigang E, Hartert M, Lonn L, Mestres CA, Di Bartolomeo R, et al Contemporary spinal cord protection during thoracic and thoracoabdominal aortic surgery and endovascular aortic repair: a position paper of the vascular domain of the European Association for Cardio-Thoracic Surgery. Eur J Cardiothorac Surg. 2015;47:943-57. 